\title{
Regulation of Discreet Intermeal Intervals in Free-feeding Rats by Exogenous IL-1beta
}

\author{
Andrew Kurt Thaw \& Kimberly A. Parker \\ Psychology Department \\ Millsaps College \\ 1701 N. State Street \\ Jackson, MS 39210
}

\begin{abstract}
This study represents an investigation of the physiology of normal feeding behavior focusing primarily on an immune factor that is hypothesized to contribute to the maintenance of the interval between meals. The immune factor interleukin-1beta (IL-1 $\beta$ ) was examined as a potential regulator of spontaneous feeding in rats with regards to satiety. Discrete patterns of feeding were analyzed to identify changes in postprandial satiety following the infusion of three concentrations of IL-1 $\beta$ as well as IL-1 Bantibody and a control saline solution. Three groups of 8 rats were fed ad libitum with food intake continuously monitored. After the first nocturnal meal, the rats received an intraperitoneal injection of either the IL-1 $\beta$ cytokine, IL-1 $\beta$ antibody or the control solution. The inter-meal interval immediately following the injection was examined to determine the effects of IL-1 $\beta$ on feeding behavior. Results indicate that exogenous $I L-1 \beta$ significantly extends the length of time between the first and second nocturnal meals. In addition, the total food intake over a $23 \mathrm{hr}$ ad libitum feeding period was significantly reduced following IL-1 $\beta$ administration. This suggests that certain cytokines act as part of the cascade of events that combine to regulate feeding and appetite in mammalian models.
\end{abstract}

Keywords: Cytokine; IL-1 $\beta$; Satiety; Intermeal interval; Food Intake

\section{Introduction}

Cytokines have been demonstrated to play a role in limiting feeding and appetite in several paradigms and species (Conn, Kozak, Tooten, Niewold, Borer, and Kluger, 1995; Fong, Moldwater and Marano, 1989; Hellerstein, Meydani, Meydani, Wu, and Dinarello, 1989; Hill, Siegel, Rounds and Wilmore, 1996; Kent, Rodriguez, and Kelly, 1994; Langhans, 1996; Langhans, Savoldelli and Weingarten, 1993; Larson, Romanoff, Dunn and Glowa, 2002; Niijima, 1996; Plata-Salaman, 1989; Plata-Salaman, 1990; Plata-Salaman, 1991; PlataSalaman, 1991a; Plata-Salaman, 1994; Plata-Salaman, 1996; Plata-Salaman, 1996a; Plata-Salaman and Borkoski, 1994; Plata-Salaman and Ffrench-Mullen, 1992; Plata-Salaman, Oomura and Kai, 1988; Uehara, Sekiya, Takasugi, Namiki and Arimura, 1989; Wong and Pinkey, 2004). These cytokines are characterized by their ability to promote fever and inflammation, yet their hypophagic response is independent of the febrile response (Plata-Salaman, 1990). In fact, these factors have been shown to alter several physiological processes involved in feeding including:

- the secretion of gut-peptides and hormones released in response to ingested food;

- stretch receptors in the stomach that indicate volumetric changes induced by the presence of food;

- the release of leptin;

- and metabolic indices of hepatic nutrient flow (Langhans and Hrupka, 1999).

Furthermore, key neural areas involved in feeding behavior are affected by cytokines. One of these areas is the glucose-sensitive neurons in the lateral hypothalamus. These neurons suppress their activity in response to interleukin-1 $\beta$ (IL-1 $\beta$ ) and tumor necrosis factor alpha (TNF $\alpha$ ) thereby decreasing their sensitivity to reduced blood glucose and lengthening the intermeal interval (IMI) (Plata-Salaman, 1990; Plata-Salaman, 1996a; PlataSalaman, 1996; Plata-Salaman, Oomura and Kai, 1988). The ventromedial hypothalamus is affected in the opposite way by IL-1 $\beta$ resulting in increased activity in glucose-sensitive neurons and decreased meal size (Daun and McCarty, 1993; Plata-Salaman, 1996a; Plata-Salaman, 1996). 
The paraventricular nucleus is stimulated by IL-1 $\beta$ and TNF $\alpha$, leading to the synthesis of corticotropin-releasing hormone which results in delays in gastric emptying and lengthening of the feelings of fullness (extended IMI)(Hermann and Rogers, 1995; Suto, Kiraly and Tache, 1994). The corticotropin-releasing hormone also inhibits the production of neuropeptide $\mathrm{Y}$ in the arcuate nucleus which further reduces food intake (Schwartz, Seeley and Woods, 2002). Also, IL-1 $\beta$ is suspected to act to increase available serotonin by facilitating the transport of tryptophan into the CNS and thus extending satiety (Miller \& Raison, 2006). More importantly, these central effects may result from peripheral increases in cytokines as well as the release of other known anorectic factors centrally (Plata-Salaman, 2000). Cytokines reportedly can enter the CNS via areas lacking the typical blood-brain barrier (Bank, Kastin, and Durham, 1989; Bank, Orits, Plotkin and Kastin, 1991). In addition, lymphocytes from the periphery release cytokines after entering the CNS (Hickey, Hsu and Kimura, 1991). Leptin is one of the most widely accepted satiety factors released from the periphery. However, Leptin does not exert its hypophagic effect when IL-1 $\beta$ activity is blocked in the third ventricle (Luhesi, Gardner, Rushforth, Loudon and Rothwell, 1999). It has been shown that key neural areas synthesize cytokines in response to peripheral signals (Plata-Salaman, 1996a; Plata-Salaman, 1996). Though the most recent studies on the effects of cytokines on feeding behavior have relied on central administration procedures (Elmquist and Saper, 1996; Gayle, Ilyin and Plata-Salaman, 1997;Kent, Rodriguez, and Kelly, 1994;Plata-Salaman, 1991a;Plata-Salaman, 1994;Plata-Salaman and Borkoski, 1994;Plata-Salaman and Ffrench-Mullen, 1992;Plata-Salaman, Oomura and Kai, 1988; Reyes and Sawchenko, 2002), the initial site of action for satiety may be peripheral due to the fact that this is where food acts to maintain normal satiation and satiety through a cascade of events (Blundell, 1991).

The majority of information examining the hypophagic effects of cytokines has been concerned with a reduction in meal size. Few studies have examined the action of peripherally-administered cytokines on the intermeal interval (Langhans, 1999). Langhans and colleagues (Langhans, Savoldelli and Weingarten, 1993) showed that acute, intraperitoneal injection of IL-1 $\beta$ just prior to dark onset reduced average meal frequency and average meal size over a12-h period during the course of repeated injections every 3 to 6 days. This study, however, only examined how many total meals that the rats ate following cytokine injection. The above mentioned study did not examine what happened to the intervals between individual meals. A study by Plata-Salaman examined the behavioral effects produced by IL-1 $\beta$ and concluded that it resulted in reduced meal sizes and longer intermeal intervals (Plata-Salaman, 1994). The extended intermeal intervals, however, did not occur until 12 hours postinjection of the cytokine, occurred during the light phase (the most variable time for intermeal intervals), and was produced via central infusions into the third ventricle. Thus, there are no studies that have employed the method reported here to examine the action of satiety factors on the intermeal interval, specifically, administering exogenous factors immediately after the end of the first nocturnal meal.

The current research investigates the role of the cytokine IL-1 $\beta$ and its effect on the intermeal interval following peripheral injections in rats. West and colleagues (West, Fey and Woods, 1984) provided a dramatic illustration that it will almost certainly be necessary to understand and control the mechanisms governing both meal size and meal frequency in order to create effective pharmacological therapies to control food intake in treating obesity. In his study, freely feeding, undisturbed rats were automatically infused with exogenous cholecystokinin (CCK) at the initiation of each spontaneous meal. CCK infusions affected meal size, as predicted, by decreasing them by about half immediately and at every subsequent meal throughout a one-week test. Within two days, however, rats doubled the frequency of the halved meals, compensating well for the continuing action of CCK on meal size (West, Greenwood, Sullivan, Prescod, Marzullo and Triscari, 1986).

The careful examination of a role for cytokines in satiety and cachexia continues. Substantial literature focuses on how cytokines affect appetite in subjects with cancer (Perboni and Inui, 2006; Konsmanet.al 2002; Laviano et.al 2000). This is a critically important area of study. However, the studies presented here differ in that the hypothesis is aimed at determining a role for cytokines in healthy subjects. Preliminary data from our lab indicates that cytokine release occurs in response to ingested food in healthy subjects and increases with increased food intake (Thaw and McGuire, 2002). This suggests that the anorexic effect of cytokines may be constantly active. The studies presented below are necessary to determine whether cytokines are capable of regulating feeding by affecting the intermeal interval immediately following administration of IL-1 $\beta$, which should be the case if these cytokines have an acute effect on satiety. In this study, the interval that occurs immediately following the first nocturnal meal after peripheral administration of exogenous IL-1 $\beta$ (as well as antibody and saline) was examined. 
Though the cytokine chosen for this study has traditionally been classified as one of the early response factors of the immune system that induce inflammation, fever and hypophagia during illnesses such as cancer (Kowalczewska, M., Wrotek, S., Jedrzejewski, T and Kozak, W. 2010; Minero. P.F., Costamagna, V.G., Bonelli, D., Baccino, G. and Costelli, F.M.P. 2010), it is hypothesized here that it also acts as one of the components important for maintaining normal feeding patterns in healthy rats. Thus, while the ability of these factors to reduce food intake, especially in pathophysiological conditions, has been extensively studied, the acute actions of these cytokines on the interval between meals in healthy subjects have not been examined.

More recently, the focus on cytokines has been on the role they may play in metabolic syndrome (Mohammadi et.al, 2017; Jialal \& Devaraj, 2018; Bremer \& Jialal, 2013). The emphasis in this line of research has been aimed at identifying the ways in which cytokines may disrupt normal insulin response. While this implicates the release of cytokines in response to feeding or obesity, a specific study identifying the effects of such an acute release of cytokines on feeding behavior has not been reported. The following research examined the acute effect of exogenously administered cytokines on feeding behavior and suggests such factors may play a crucial role in satiety.

\section{Subjects}

24 male Sprague-Dawley (Harlan) rats weighing 200-250g were housed individually in a room maintained at a constant temperature of $72^{\circ} \mathrm{F}\left(22.2^{\circ} \mathrm{C}\right)$. The subjects were tested in three sequential groups $(\mathrm{N}=8$ for each group), with each rat receiving saline injections (control) as well as injections of IL-1 $\beta$ (2ug/kg, $4 \mathrm{ug} / \mathrm{kg}$ and $8 \mathrm{ug} / \mathrm{kg}$ body weight) and IL-1 $\beta$ antibodies (100ug/kg body weight). A $12 \mathrm{~h}$ light $/ 12 \mathrm{~h}$ dark cycle was maintained, with lights out at $1300 \mathrm{~h}$. Rats had free access to water and powdered rat chow (LM-485 Harlan-Teklad, Madison, WI) throughout the study.

\section{Apparatus}

Feeding behavior was monitored using specially designed open-topped, polycarbonate cages with stainless steel mesh floors (floor area, $896 \mathrm{~cm}^{2}$; height $50 \mathrm{~cm}$ ) and a niche area constructed of a solid piece of L-shaped stainless steel $(11 \mathrm{~cm}$ wide $\times 10 \mathrm{~cm}$ deep x $30 \mathrm{~cm}$ high) (DiLog, Tallahassee, FL). Each cage had a water bottle that protruded through a standard lick-block to record each lick on the tube as well as a spill-resistant food cup mounted under a single, recessed food access area on the rear of the cage. The size of each individual meal was not measured directly. Instead, infra-red light-emitting diodes and phototransistors were positioned at the entrance to the food area so that eating by the rat interrupted the beam. The feeding area was triangular in shape allowing rats to easily place their heads over the food cup, yet preventing them from entering further. Beam breaks were transmitted to a computer in an adjoining room and stored for analysis. Periods of beam breaks were interpreted as periods of feeding after the demonstration that Pearson product-moment correlation between direct measurements of food consumption $(\mathrm{g})$ and beam break durations $(\mathrm{sec})$ were 0.9 or greater in separate short- and long-term tests.

The data was comprised of durations of beam breaks or time without beam breaks and was grouped into 6-second time intervals. The initiation of a feeding bout was defined as a beam break occurring for at least 3 seconds during a 6-second time interval. If there were no beam breaks for 50 consecutive 6-second time intervals (300 consecutive seconds or 5 minutes), this was defined as the termination of a meal. Feeding bouts with less than 30 total seconds of activity were not defined as meals. Excluding this data resulted in the elimination of an average of 20 seconds of activity out of a total average of 6200 seconds of activity during the 23 -hour feeding periods. An intermeal interval was defined as the time between the termination of a meal and the initiation of the next meal.

\section{Procedure}

Following arrival, the rats were acclimated to laboratory and test chamber conditions, light cycle, and testing schedule for 21 days. The room was kept at a constant temperature of $72^{\circ} \mathrm{F}\left(22.2^{\circ} \mathrm{C}\right)$. Rats were tested in three sequential groups ( $\mathrm{N}=8$ for each group), each rat serving as its own control. Each rat received saline injections (control) as well as injections of IL-1 $\beta$ ( $2 \mathrm{ug} / \mathrm{kg}$, $4 \mathrm{ug} / \mathrm{kg}$ and $8 \mathrm{ug} / \mathrm{kg}$ body weight) and IL- $1 \beta$ antibodies $(100 \mathrm{ug} / \mathrm{kg}$ body weight). The cytokine products were purchased from Biodesign (Camarillo,CA). The chosen dosage of IL$1 \beta$ represents the amount of the cytokine demonstrated to significantly reduce feeding behaviors in rats when administered peripherally (Hellenstein, Meydani, Meydani, Wu and Dinarello, 1989;Langhans, Savoldelli and Weingarten, 1993;Plata-Salaman, 1989;Thaw, 2000;Uehara, Sekiya, Takasugi, Namiki and Arimura,1989). 
Daily maintenance and provision of fresh food and water were carried out between $0900 \mathrm{~h}$ and $1000 \mathrm{~h}$. At $1000 \mathrm{~h}$ recording and storage of sequential beam breaks began and continued throughout the next $23 \mathrm{~h}$. At $1255 \mathrm{~h}$ the experimenter entered the room adjacent to the test room where monitoring of the rats feeding behavior could be observed using a computer generated display of beam-break activities for each of the eight rats. Lights went out at 1300. Immediately after the completion of the first nocturnal meal (5 consecutive minutes with no beam breaks) for each rat, the experimenter entered the room, removed the rat from the cage, administered an intraperitoneal injection of $0.15 \mathrm{M} \mathrm{NaCl}(1 \mathrm{ml} / \mathrm{kg}$ body weight), replaced the rat in its cage, and returned to the computer monitor. Using this procedure, 4 days of baseline data were collected and acclimated the rats to the test conditions prior to the introduction of cytokines or antibodies.

Testing began at the completion of the 4 day acclimation period. At the end of the first nocturnal meal, rats received a single intraperitoneal injection (Weingarten, 1996) of either the cytokine $(2,4$, or $8 \mathrm{ug} / \mathrm{kg}$ ), cytokine antibodies $(100 \mathrm{ug} / \mathrm{kg})$ or saline as the control. Injection volumes were adjusted on the basis of daily body weight measurements so that concentrations for particular doses remained constant. At least 48 hours separated cytokine administration to an individual rat and injections were delivered using a counterbalancing procedure so that half of the rats received the control and half received cytokine or antibodies each day. The cytokines and antibodies were delivered twice to each rat as well as 2 saline/control injections between each cytokine or antibody injection for a total of 28 consecutive days of testing.

\section{Data Analysis}

Statistical comparisons of the intermeal interval after control and cytokine/antibody injections were carried out using a repeated measures t-test. Multiple control (saline) injections were administered throughout the study to provide numerous potential comparisons. It was determined that the best comparison would be to examine the IMI's following meals of similar size. By collecting data from multiple control injections (a total of 20 saline control injections were administered) we were able to have each rat serve as its own control and utilize data from the first nocturnal meal that varied by $5 \%$ or less for each comparison. This assured that rats were in a similar state of satiety before and after meal 1 . The matched t-test was used to compare the IMI data instead of an ANOVA due to the fact that our meal-matching procedure lead to different control data being used for each cytokine concentration. In other words, since the length of the first nocturnal meal varied (meal 1 data) throughout the study it was necessary to use matching control data depending on the meal size from the cytokine injection (see Figure 1). The alpha level was set at 0.05 for all statistical tests.

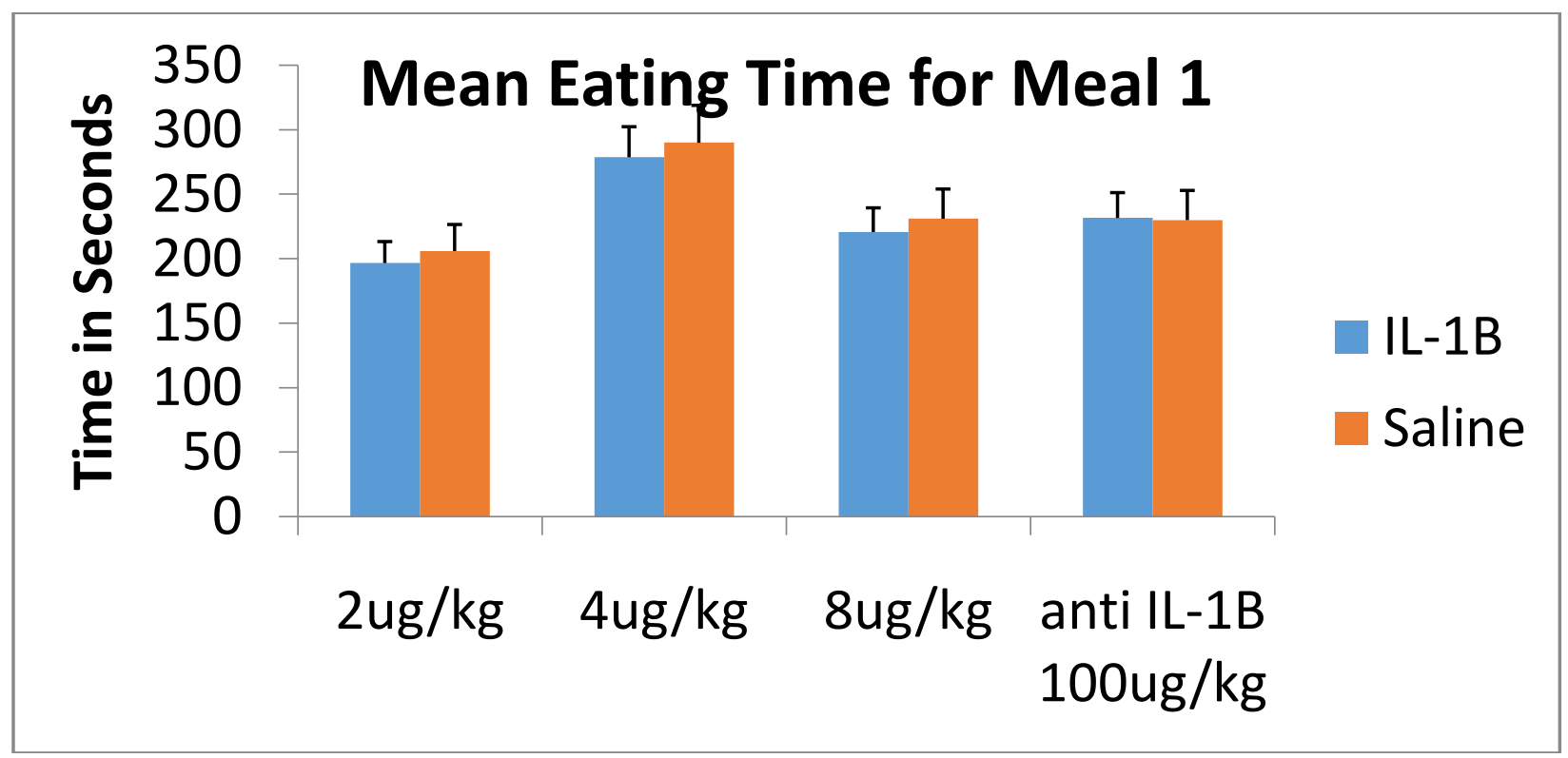

\section{Figure 1}

The mean, first nocturnal meal (in seconds) for control and experimental groups. Data was matched using each subject as its own control resulting in less than a 5\% difference between control and experimental data. 


\section{Results}

The peripheral, systemic administration of IL- $1 \beta$ produced significant increases in the postprandial intermeal interval of free feeding rats $(\mathrm{p}<0.05)$. IL- $1 \beta$ at doses of 2,4 , and $8 \mathrm{ug} / \mathrm{kg}$ body weight lengthened intermeal intervals by an average of $54.39 \%, 38.86 \%$ and $31.58 \%$ respectively (Figure 2). IL-1 $\beta$ antibody injections at a dose of $100 \mathrm{ug} / \mathrm{kg}$ body weight resulted in a non-significant average intermeal interval decrease of $10.27 \%$ (Figure 2).

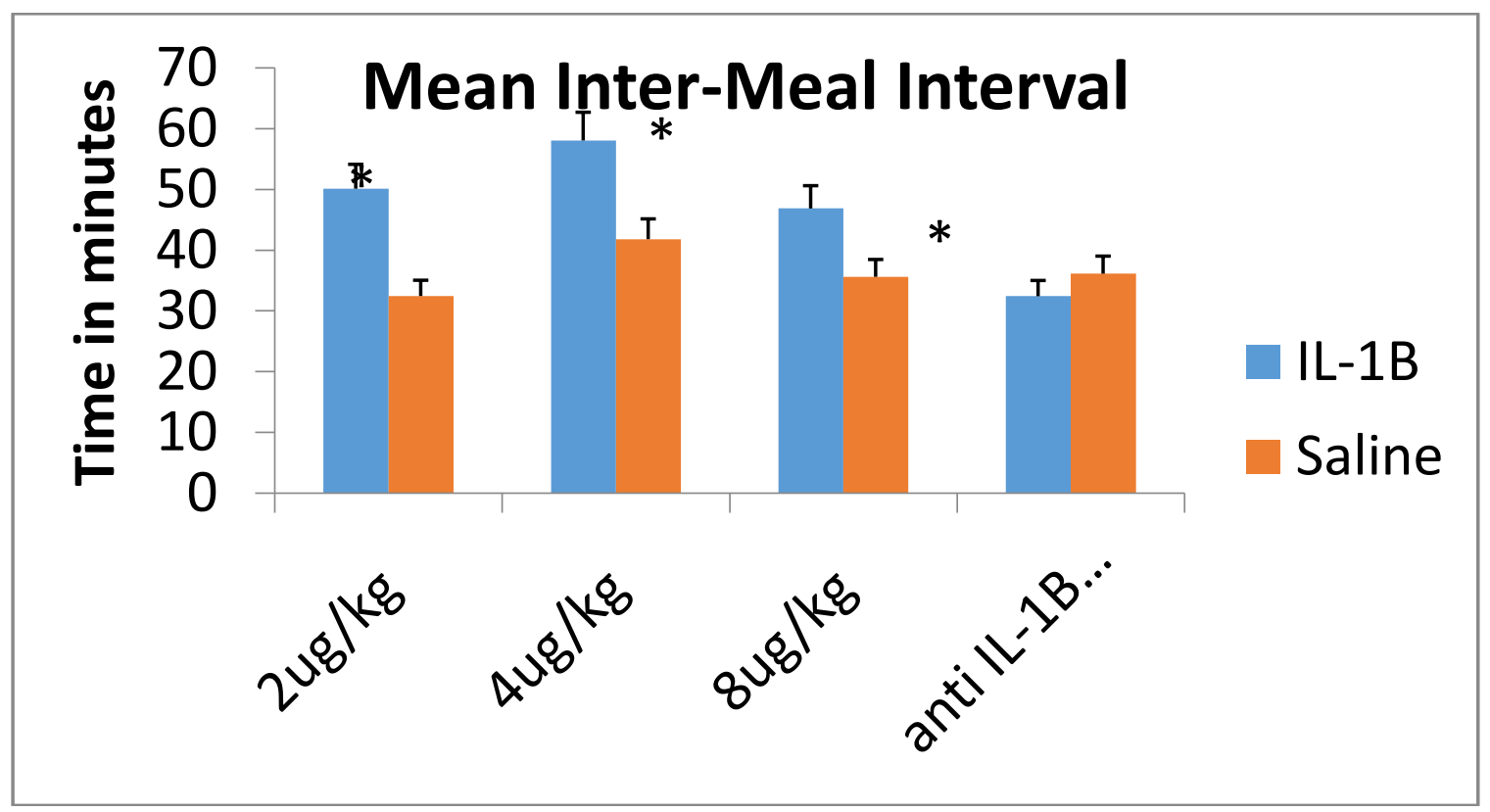

Figure 2

Effects of IL-1 $\beta$ on the firtst nocturnal inter-meal interval. * Significant differences $(p<0.05)$ were found for the cytokine administration, but not the antibody using matched t-tests for each comparison.

Additionally, IL-1 $\beta$ administration led to significantly reduced mean cumulative food intake compared to control solutions over the $23 \mathrm{hr}$ period during which exogenous IL-1 $\beta$ was delivered (Table 1 ). This was surprising given that the effects of the cytokine injections were limited to the first nocturnal IMI and did not have significant effects on subsequent meals of IMIs.

Table 1. Cumulative 23hr Food Intake

\begin{tabular}{l|cc|cc|}
\multicolumn{1}{c}{} & \multicolumn{1}{c}{ Saline } & \multicolumn{1}{c}{ IL-IB } & Saline & Anti IL-1B \\
\cline { 2 - 5 } $2 \mathrm{ug} / \mathrm{kg}$ & 27.28 & 25.3 & 26.16 & 29.25 \\
$4 \mathrm{ug} / \mathrm{kg}$ & 38.23 & 33.6 & 32.65 & 32.41 \\
$8 \mathrm{ug} / \mathrm{kg}$ & 33.77 & 30.6 & 28.02 & 29.92 \\
& & & & \\
Total & 33.09 & $29.78^{*}$ & 28.95 & 30.53 \\
\hline
\end{tabular}

* Significant difference using Repeated Measures ANOVA $(p<0.05)$

Correlations between meal size and IMI were also examined to determine the extent to which the cytokines may be affecting this relationship between meal size and IMI. It should be noted that there exists a modest correlation between meal size and subsequent IMI in our apparatus which does appear to be consistent $(r=0.33)$. Thus, significant changes in either the meal size or IMI will result in a correlation coefficient even lower than the $r=$ 0.33 normally observed in our lab (Table 2). By comparing all of our IL-1 $\beta$ injection data with its matched control data we found the correlation to be reduced to $r=0.20$. 
This is further evidence supporting a role of $\mathrm{IL}-1 \beta$ in the modulation of satiety. There was virtually no change in the correlation for the antibody injection $(r=0.34)$

Table 2Beam break/Food consumption correlation

\begin{tabular}{|c|c|c|c|}
\hline Saline & $r=0.31$ & IL-1B $2 \mathrm{ug} / \mathrm{kg}$ & $\mathrm{r}=0.21$ \\
\hline $\begin{array}{l}\text { IL-1B } \\
\text { antibody }\end{array}$ & $r=0.34$ & & $r=0.19$ \\
\hline Baseline & $\mathbf{r}=\mathbf{0 . 3 1}$ & IL-1B $8 \mathrm{ug} / \mathrm{kg}$ & $r=0.24$ \\
\hline
\end{tabular}

Though not significant, the cytokine injections disrupted the correlation between length of time eating and total grams of food consumed. Saline injections had no effect.

The first nocturnal meal varied in total time from 1 to 8 minutes in the current study. To determine if the size of a meal impacted the effect of our cytokine injection the data was divided into 3 groups based on meal sizes of 1-2 minutes, 2-4 minutes and 4-8 minutes (meal size is defined as the actual time spent feeding, not elapsed time from meal initiation to termination).

Independent t-tests were used for this analysis, since the number of meals were not identical for control and cytokine/antibody groups. Although all IL-1 $\beta$ data show large increases in the IMI compared to control injections, the difference is significant only for the 1-2 and 2-4 minute meals. This is due to the fact that as meals increase in size the IMI for controls also increased making statistical differences less likely to be discernable.

For the IL-1 $\beta$ antibody data, the IMI was different for the antibody (in this case lower) compared to control for all groups, however significant differences were found for meals of 2-4 minutes duration only (Table 3).

Table 3. Beam break/Food consumption correlation

\begin{tabular}{|c|c|c|c|}
\hline & $1-2 \mathrm{~min}$ & $2-4 \mathrm{~min}$ & 4-8 min \\
\hline IL-1B $2 u g / k g$ & $39.3 * *$ & $58 *$ & 62 \\
\hline IL-1B $4 \mathrm{ug} / \mathrm{kg}$ & $44 * *$ & $52 * *$ & 74 \\
\hline $\begin{array}{l}\text { IL-1B } 8 \mathrm{ug} / \mathrm{kg} \\
\text { IL-1B } \\
\text { antibody }\end{array}$ & $\begin{array}{l}32 * \\
24 \\
\end{array}$ & $\begin{array}{l}48 * \\
31 * \\
\end{array}$ & $\begin{array}{l}68 \\
45 \\
\end{array}$ \\
\hline $\mathrm{N}=$ & 68 & 104 & 20 \\
\hline grand mean & $\begin{array}{l}\frac{34.825}{*} \\
* \text { = Sign } \\
* * \text { Sign } \\
\text { Data wa } \\
\text { calculat } \\
\text { Matchea } \\
\text { repeated } \\
\text { N repres } \\
\text { variable }\end{array}$ & $\begin{array}{l}\frac{47.25}{\text { ing repea }} \\
\text { ing repea } \\
\text { ng results } \\
\text { s were us } \\
\text { er of data }\end{array}$ & $\begin{array}{l}\frac{62.25}{<0.05)} \\
<0.01) \\
\text { and } \\
\text { alculate the } \\
\text { each time }\end{array}$ \\
\hline
\end{tabular}

With respect to additional meals and IMI's for the nocturnal cycle, there were no significant effects of treatment on the size of any subsequent meal or the duration of any other intermeal intervals during the $23 \mathrm{~h}$ test period. 
Differences in subsequent meals and intermeal intervals do exist, however the variability of the data is so extreme as to make interpretation difficult and results in no statistical significance. Thus, observable effects were limited to the intermeal interval during which treatment was delivered.

Videotaped observations of the animals beginning immediately after injection and continuing for 2-hours revealed no abnormal behaviors. Rats groomed, explored the cage environment, or rested, apparently asleep during this observation period. These behaviors are part of the typical post-prandial behavior pattern (Antin, Gibbs, Holt, Young and Smith, 1975).

\section{Discussion}

The results of this study indicate that the cytokine IL-1 $\beta$ may play a role in the physiological regulation of appetite in the healthy, free-feeding rat. Though considerable research has examined the effects of cytokines on feeding behavior, this is the first focused effort to implicate a cytokine as a potential acute regulator of the interval between meals. Specifically, IL-1 $\beta$ administration significantly extended the length of time between the first and second nocturnal meals. Even when accounting for the effects of meal size on the IMI by matching procedures, IL-1 $\beta$ maintained its significant effect of extending satiety. The significant reduction in total food intake following IL-1 $\beta$ injection is surprising due to the fact that discrete feeding behavior was targeted, theoretically affecting only one eating episode. The resultant decrease in total feeding suggests that the extended satiety produced with exogenous IL-1 $\beta$ administration is not recovered by eating larger meals or more frequent meals following the injection. In fact, the data indicates no substantive changes in meal frequency or size following IL$1 \beta$ injections (Figure 1).

The results of this study provide evidence that IL1- $\beta$ is an important satiety factor having similar effects on feeding behavior as other putative satiety factors such as CCK and Bombesin-like peptides.Though previous studies have revealed the involvement of the immune system in feeding, the discreet behaviors involved in feeding presented here extend those findings and demonstrate the direct action of cytokines on the IMI (satiety) in healthy rats. The promising results suggest that IL- $1 \beta$ may play a part as one of the factors released in the cascade of events that occurs in response to ingested nutrients. In fact, pilot data from our lab (Thaw and McGuire, 2002) confirms a spontaneous release of IL- $1 \beta$ from the intestines of rats in response to food intake. This increase appears to occur in a dose response manner whereby the more food consumed, the more cytokine released. Continued research in this area is needed to establish cytokines as a physiological regulator of appetite in normal healthy mammalian models.

To conclude, this research provides evidence for an effect of exogenously delivered immune factors on spontaneous feeding behavior in healthy rats. It identifies the nature of such regulation by examining the discrete patterns of feeding, as well as identifying changes in postprandial satiety behaviors following the injection of various doses of the cytokine IL-1 $\beta$. The results provide support for further investigation of the actions of cytokines in the physiological maintenance of satiety.

\section{Acknowledgements}

The author wishes to thank Dr. James Gibbs for his helpful comments and guidance in the completion of this manuscript. Also, this research would not have been possible without the dedicated efforts of Steven Murphy and Sarah Todd. This study was made possible with generous grants from the New York Obesity Research Center and the National Institutes of Health (1R15DK57578-01A1).

\section{Literature Cited}

Antin, J., Gibbs, J., Holt, J., Young, R.C., and Smith, G.P. Cholecystokinin elicits the complete behavioral sequence of satiety in rats. J. Comp. Physiol. Psychol. 89: 784-790, 1975.

Banks, W.A., Kastin, A.J., Durham, D.A. Bidirectional transport of interleukin-1 alpha across the blood-brain barrier. Brain Res, Bull. 23: 433-437, 1989.

Banks, W.A., Oritz, L., Plotkin, S.R., Kastin, A.J. Human interleukin (IL) 1 alpha, murine IL-1 alpha and murine IL-1 beta are transported from blood to brain in the mouse by a shared saturable mechanism. J. Pharmacol. Exp. Ther. 259: 988-996, 1991.

Blundell, J. Pharmacological approaches to appetite suppression. Trends Pharmacol. Sci. 12(4): 147-157, 1991. 
Bremer, A. A., \& Jialal, I. (2013). Adipose Tissue Dysfunction in Nascent Metabolic Syndrome. Journal of Obesity, 2013, 393192. doi.org/10.1155/2013/393192

Conn, C.A., Kozak, W.E., Tooten, P.C., Niewold, T.A., Borer, K.T., Kluger, M.J. Effect of exercise and food restriction on selected markers of the acute phase response in hamsters. J. Appl. Physiol. 78(2): 458-465, 1995.

Daun, J.M., McCarty, D.O. The role of cholecystokinin in interleukin-1-induced anorexia. Physiol. Behav. 54: 237-241, 1993.

Elmquist, J.K. and C.B. Saper. Activation of neurons projecting to the paraventricular hypothalamic nucleus by intravenous lipopolysaccharide. Journal of Comparative Neurology 374: 315-331, 1996.

Fong, Y., Moldawer, L.L., Marano, M., et al. Cachectin/TNF or IL-1 alpha induces cachexia with redistribution of body proteins. Am. J. Physiol. 256:R659-R665, 1989.

Gayle, D., S.E. Ilyin, and Plata-Salaman, C.R. Central nervous system IL-1 beta system and neuropeptide Y mRNAs during IL-1 beta-induced anorexia in rats. Brain Res Bull 44: 311-317, 1997.

Hellerstein, M.K., Meydani, S.N., Meydani, M., Wu, K., Dinarello, C.A. Interleukin-1-induced anorexia in the rat. Influence of prostaglandins. J.Clin. Invest. 84:228-235, 1989.

Hermann, G., Rogers, R.C. Tumor necrosis factor-alpha in the dorsal vagal complex suppresses gastric motility. Neuroimmunomodulation 2: 74-81, 1995.

Hickey, W.F., Hsu, B.L., Kimura, H. T-lymphocyte entry into the central nervous system. J. Neurosci. Res. 28: 254-260, 1991.

Hill, A.G., J. Siegel, J. Rounds, and D.W. Wilmore. Metabolic responses to interleukin-1: Centrally and peripherally mediated. Annals of Surgery 225: 246-251, 1997.

Jialal, I. \& Devaraj, S. (2018). Subcutaneous adipose tissue biology in metabolic syndrome. Hormone Molecular Biology and Clinical Investigation, 33(1), 2018. doi:10.1515/hmbci-2017-0074

Kent, S., Rodriguez, F, Kelley, K.W., et al. Reduction in food and water intake induced by microinjection of interleukin-1 beta in the ventromedial hypothalamus of the rat. Physiol. Beh. 56:1031-1036, 1994.

Konsman, J.P., Parnet, P. \& Dantzer, R. Cytokine induced sickness behavior: mechanisms and implications. Trend Neurosci. 143, 154-159, 2002.

Kowalczewska, M., Wrotek, S., Jedrzejewski, T and Kozak, W. Cancer cachexia: mediating factors and the effect of eicosapentaenoic acid dieting. J PreClin and Clin research, vol.4, 2, pp.108-111. 2010

Langhans, W. Bacterial products and the control of ingestive behavior: clinical implications. Nutrition 12: 303315, 1996.

Langhans, W., Hrupka, B. Interleukins and tumor necrosis factor as inhibitors of food intake. Neuropeptides 33(5): 415-424, 1999.

Langhans, W., Savoldelli, D., and Weingarten, S. Comparison of the feeding responses to bacterial lipopolysaccharide and interleukin-1 $\square$. Physiol. Beh. 53(4):643-649, 1993.

Larson, S.J., Romanoff, R.L., Dunn, A.J., and Glowa, J.R. Brain Behav Immun, 16(4):398-410, 2002.

Laviano, A, Gleason, J.R., Meguid, M.M., Yang, Z.J., Cangiano, C. \& Rossi-Fanelli, F. Effecs of intraVMN mianserin and IL-1b on meal number in anorectic tumor-bearing rats. J Invet. Med. 48, 40-48, 2000.

Luhesi, G.N., Gardner, J.D., Rushforth, D.A., Loudon, A.S. and Rothwell, N.J. Leptin actions on food intake and body temperature are mediated by IL-1. Neurobiology, 96(12):7047-7052, 1999.

Miller, A.H. and Raison, C.L. Cytokines, p38 MAP Kinase and the Pathophysiologyof Depression. Neuropsychopharmacology 31, 2089-2090, 2006.

Minero. P.F., Costamagna, V.G., Bonelli, D., Baccino, G. and Costelli, F.M.P. Anti-cytokine strategies for the treatment of cancer-related anorexia and cachexia.Expert Opin Biol Ther. Aug;10(8):1241-50, 2010.

Mohammadi, M., Gozashti, M. H., Aghadavood, M., Mehdizadeh, M. R., \& Hayatbakhsh, M. M. (2017). Clinical Significance of Serum IL-6 and TNF- $\alpha$ Levels in Patients with Metabolic Syndrome. Reports of Biochemistry \& Molecular Biology, 6(1), 74-79.

Niijima, A. The afferent discharges from sensors for interleukin-1beta in the hepatoportal system in the anesthetized rat. Journal of the Autonomic Nervous System 61: 287-291, 1996.

Perboni, S. and Inui, A. Anorexia in cancer: role of feeding regulatory peptides. Phil Trans. R. Soc. B, 361:12811289, 2006.

Plata-Salaman, C.R., Oomura, Y., Kai, Y. Tumor necrosis factor and interleukin-1 beta: Suppression of food intake by direct action in the central nervous system. Brain Res. 448:106-114, 1988. 
Plata-Salaman, C.R. Immunomodulators and feeding regulation: A humoral link between the immune and nervous systems. Brain Behav. Immun. 3:193-213, 1989.

Plata-Salaman, C.R. Immunoregulators in the nervous system. Neurosci. Biobeh. Rev. 15(2): 185-215, 1990.

Plata-Salaman, C.R. Regulation of hunger and satiety in man. Dig. Dis. 9:253-268, 1991.

Plata-Salaman, C.R. Dexamethasone inhibits food intake suppression induced by low doses of interleukin-1 beta administered intracerebroventricularly. Brain Res. 27:737-738, 1991a.

Plata-Salaman, C.R., Ffrench-Mullen, J.M. Intracerebroventricular administration of a specific IL-1 receptor antagonist blocks food and water suppression induced by interleukin-1 beta. Physiol. Beh. 51:1277-1279, 1992.

Plata-Salaman, C.R. Meal patterns in response to the intracerebroventricular administration of interleukin-1 $\beta$ in rats. Phys. Beh. 55(4):727-733, 1994.

Plata-Salaman, C.R., Borkoski, J.P. Chemokines/intercrines and central regulation of feeding. Am. J. Physiol. 266:R1711-R1715, 1994.

PlataSalaman, C.R. Anorexia during acute and chronic disease. Nutrition 12: 69-78,1996.

Plata-Salaman, C.R. Cytokine action in the nervous system at pathophysiological versus pharmacological concentrations. AIDS, Drugs of Abuse, and the Neuroimmune Axis. Edited by Friedman et al., Plenium Press, New York, 1996a.

Plata-Salaman, C.R. Central nervous systems mechanisms contributing to the cachexia-anorexia syndrome. Nutrition 16, 1009-1012, 2000.

Reyes, T.M. and Sawchenko, P.E. Involvement of the arcuate nucleus of the hypothalamus ininterleukin-1induced anorexia. J. Neurosci, 22(12):5091-5099, 2002.

Schwartz, M.W., Seeley, R.J., Woods, S.C. Wasting illness as a disorder of body weight regulation. Proc. Nutr. Soc. 56: 785-791, 1997

Suto, G., Kiraly, A., Tache, Y. Interleukin-1 beta inhibits gastric emptying in rats: mediation through prostaglandin and corticotropin-releasing factor. Gastroenterology 106: 1568-1575, 1994.

Thaw, A. K. Physiological Regulation Of The Intermeal Interval In Rats By IL-1 . (abstract) J.Experimental Biology, 2000.

Thaw, A.K. \& S. McGuire. The Spontaneous Release Of Cytokines In Response To Ingested Nutrients. (abstract) Experimental Biology, 2002.

Uehara, A., Sekiya, C., Takasugi, Y., Namiki, M, Arimura, A. Anorexia induced by interleukin-1: Involvement of corticotropin-releasing factor. Am. J. Physiol. 257:R613-R617, 1989.

Weingarten, H.P. Cytokines and food intake: The relevance of the immune system to the student of ingestive behavior. Neurosci. Biobehav. Rev. 20(1): 163-170, 1996.

West, D.B., Fey, D., and Woods, S.C. Cholecystokinin persistently suppresses meal size but not food intake in free-feeding rats. Am. J. Physiol. 246:R776-R787, 1984.

West, D.B., Greenwood, M.R.C., Sullivan, A.C., Prescod, L., Marzullo, L.R., and Triscari, J. Infusion of cholecystokinin between meals into free-feeding rats fails to prolong the intermeal interval. Phys. Behav. 39: 111-115, 1986.

Wong, S. and Pinkey, J. Role of cytokines in regulating feeding behaviour. Curr Drug Targets, 5(3):251-263, 2004. 